\title{
Hypocretin/Orexin Neurons Contribute to Hippocampus- Dependent Social Memory and Synaptic Plasticity in Mice
}

\author{
Liya Yang, ${ }^{1}$ Bende Zou, ${ }^{1}$ Xiaoxing Xiong, ${ }^{2}$ Conrado Pascual, ${ }^{1}$ James Xie, ${ }^{1,3}$ Adam Malik, ${ }^{1}$ Julian Xie, ${ }^{1}$ Takeshi Sakurai, ${ }^{4}$ \\ and Xinmin (Simon) Xie ${ }^{1,2}$ \\ ${ }^{1}$ AfaSci Research Laboratories, Redwood City, California 94063, 2 Department of Anesthesia, Stanford University School of Medicine, Stanford, California \\ 94305, ${ }^{3}$ Stanford University School of Medicine, Stanford, California 94305, and ${ }^{4}$ Department of Molecular Neuroscience and Integrative Physiology, \\ Faculty of Medicine, Kanazawa University, Kanazawa 920-1192, Japan
}

Hypocretin/orexin (Hcrt)-producing neurons in the lateral hypothalamus project throughout the brain, including to the hippocampus, where Hcrt receptors are widely expressed. Hcrt neurons activate these targets to orchestrate global arousal state, wake-sleep architecture, energy homeostasis, stress adaptation, and reward behaviors. Recently, Hcrt has been implicated in cognitive functions and social interaction. In the present study, we tested the hypothesis that Hcrt neurons are critical to social interaction, particularly social memory, using neurobehavioral assessment and electrophysiological approaches. The validated "two-enclosure homecage test" devices and procedure were used to test sociability, preference for social novelty (social novelty), and recognition memory. A conventional direct contact social test was conducted to corroborate the findings. We found that adult orexin/ataxin-3-transgenic (AT) mice, in which Hcrt neurons degenerate by 3 months of age, displayed normal sociability and social novelty with respect to their wild-type littermates. However, AT mice displayed deficits in long-term social memory. Nasal administration of exogenous Hcrt-1 restored social memory to an extent in AT mice. Hippocampal slices taken from AT mice exhibited decreases in degree of paired-pulse facilitation and magnitude of long-term potentiation, despite displaying normal basal synaptic neurotransmission in the CA1 area compared to wild-type hippocampal slices. AT hippocampi had lower levels of phosphorylated cAMP response element-binding protein (pCREB), an activity-dependent transcription factor important for synaptic plasticity and long-term memory storage. Our studies demonstrate that Hcrt neurons play an important role in the consolidation of social recognition memory, at least in part through enhancements of hippocampal synaptic plasticity and cAMP response element-binding protein phosphorylation.

\section{Introduction}

Hypocretin/orexin (Hcrt)-producing neurons in the lateral hypothalamus project broadly to the entire CNS, including the hippocampus (Peyron et al., 1998; Sakurai et al., 1998; de Lecea et al., 1998). Hcrt peptides (Hcrt-1/orexin A and Hcr-2/orexin B) participate in neuronal regulation by activating their receptors (Hcrt-1R/OX1R and Hcrt-2R/OX2R), thus contributing to arousal, alertness, sleep, appetite and feeding, and balance between metabolism and energy expenditure (Kilduff, 2005; Carter et al., 2009; de Lecea, 2010; Sakurai and Mieda, 2011). Furthermore, Hcrt neuronal activity has been implicated in the modu-

Received July 5, 2012; revised Jan. 31, 2013; accepted Feb. 11, 2013.

Author contributions: L.Y., B.Z., James Xie, and X.(S.)X. designed research; L.Y., B.Z., X.X., C.P., A.M., and X.(S.)X. performed research; T.S. and X.(S.)X. contributed unpublished reagents/analytic tools; L.Y., B.Z., X.X., C.P., A.M., Julian Xie, and X.(S.)X. analyzed data; James Xie, Julian Xie, and X.(S.)X. wrote the paper.

This work was supported by the National Institutes of Health (Grants R01MH078194, R44DA026363, R43NS065555, R43MH076309, R41HL84990, and R43 NS073311). We thank T.S. Chen and Drs. S. Black and T. Kilduff at SRI International for kindly providing some AT and WT mice used in this study and interns Carlos Sanchez, Gregory Frane, Waranga Safi, Sandie Luo, and Zhaohui Li at AfaSci Research Laboratories for assistance in animal care and experiments.

The SmartCage system, developed by AfaSci, was used to monitor animal behavior, social interaction, and social memory at homecage in this study. X. Xie is the founder and owner of AfaSci.

Correspondence should be addressed to Dr. Xinmin (Simon) Xie, AfaSci Research Laboratories, 522 Second Avenue, Redwood City, CA 94063. E-mail: simonxie@afasci.com.

DOI:10.1523/JNEUROSCI.3200-12.2013

Copyright $\odot 2013$ the authors $\quad 0270-6474 / 13 / 335275-10 \$ 15.00 / 0$ lation of stress-adaptive responses, including stress-induced analgesia (Xie et al., 2008; Gerashchenko et al., 2011), and anxiogenesis (Winsky-Sommerer et al., 2004; Johnson et al., 2010), neuroprotection against focal cerebral ischemia via attenuation of inflammatory responses (Xiong et al., 2013), reward behavior (Harris et al., 2005; Perello et al., 2010; Sharf et al., 2010; McGregor et al., 2011), and learning and memory (Jaeger et al., 2002; Fadel and Burk, 2010; Selbach et al., 2010). Nasal administration of Hcrt-1 improved cognitive performance in sleep-deprived nonhuman primates (Deadwyler et al., 2007). Alterations in Hcrt regulation of septohippocampal cholinergic activity has been link to age-related dysfunctions in arousal, learning, and memory (Stanley and Fadel, 2012).

A clinical study using microdialysis to measure Hcrt-1 in the temporal and frontal lobe areas of refractory epileptic patients found a substantial increase in the extracellular Hcrt-1 level when the patients interacted with people, especially their relatives (Blouin et al., 2013). Social interaction requires social memory, including encoding, storing, and retrieving for processing and retaining information about conspecifics. The hippocampus has an important role in social recognition memory in humans (O'Kane et al., 2004) and rodents (Kogan et al., 2000; Nomoto et al., 2012). The formation of long-term memory in several hippocampus-dependent cognitive tasks, including social recognition, requires cAMP response element-binding protein 
(CREB), an activity-dependent gene transcription. Neurotransmitters such as dopamine, serotonin, and acetylcholine, which enhance memory, induce CREB phosphorylation (Bourtchuladze et al., 1994; Silva et al., 1998; Kogan et al., 2000; Shirayama and Chaki, 2006); however, little is known about the function of Hcrt neurons in social interaction and memory, and their physiological roles in the modulation of hippocampal synaptic plasticity and CREB activity.

In the present study, we studied the role of Hcrt in social interaction, especially social memory, using orexin/ataxin-3transgenic (AT) mice, in which Hcrt neurons degenerate by 3 months of age (Hara et al., 2001). We investigated three components of social interaction (Crawley, 2004; Riedel et al., 2009): (1) sociability: social approach behavior toward unfamiliar conspecifics; (2) social novelty: the preference to interact with a novel conspecific compared with a familiarized one; and (3) social memory: the retention of social recognition over a period of time between sociability and social novelty tests. We found that, compared with their wild-type (WT) littermates, AT mice exhibited normal sociability and social novelty, but had shorter social recognition memory. Attenuated paired pulse facilitation (PPF) and long-term potentiation (LTP) and decreased phosphorylated CREB (pCREB) levels in the AT hippocampus compared with the WT hippocampus may underlie mechanisms of the long-term social memory deficit in AT mice.

\section{Materials and Methods}

Animals. Adult male and female mice (AT and WT C57BL/6 littermates, 3-6 months of age) were used. Animals were group housed under standard laboratory conditions and kept on a normal light/dark cycle (lights on at 7:00 A.M.; lights off at 7:00 P.M.). All studies were conducted in accordance with protocols approved by the Institutional Animal Care and Use Committees at AfaSci and SRI International, and the NIH Guide for the Care and Use of Laboratory Animals. Production of transgenic mice followed the procedure described previously (Hara et al., 2001). Presence and copy numbers of the transgene in the offspring were identified by PCR analysis of tail DNA.

Immunohistochemistry and homecage activity monitoring. Hcrt-positive neurons were detected with goat anti-orexin-B antibody (1:100; Santa Cruz Biotechnology) and using the optical fractionator method on epifluorescence photomicrographs (Axiovert inverted fluorescent microscope; Zeiss). The SmartCage system (AfaSci) was used for automated analysis of spontaneous activity in the animal's homecages ( $\mathrm{L} 29.8 \mathrm{~cm}, \mathrm{~W} 18.0 \mathrm{~cm}, \mathrm{H} 12.8 \mathrm{~cm}$; Allentown) as described previously (Khroyan et al., 2012). The homecage activity variables (locomotion, travel distance, velocity, and rear-ups) were determined by photobeam breaks and were analyzed automatically using CageScore software (AfaSci). Both AT and WT mice were simultaneously assessed for $48 \mathrm{~h}$ during the light/dark cycle and the second $24 \mathrm{~h}$ record was plotted in hourly blocks and presented in Figure 1.

Automated two-enclosure homecage social test. The two-enclosure homecage tests (Khroyan et al., 2012) were mostly conducted during the light phase, and several experiments were conducted during the first $3 \mathrm{~h}$ of the dark phase as specified in the figure legends. Two transparent Plexiglas enclosures $(\mathrm{W} 8 \times \mathrm{D} 6 \times \mathrm{H} 12 \mathrm{~cm}$ ) with a metal mesh floor were attached at both end walls of a fresh homecage. The social interaction test consisted of three 10 min sessions based on published procedures (Crawley, 2004; Nadler et al., 2004): (1) habituation, in which the test subject freely explored a homecage with two empty enclosures (nonsocial cues); (2) sociability test, in which the test subject investigated a stimulus mouse designated "Stranger 1," taken from a homecage different from the test subject's one. The Stranger 1 was pseudorandomly placed in one of the enclosures; and (3) social novelty test, in which the test subject had the choice of what to investigate, Stranger 1 or a novel mouse designated "Stranger 2," which was taken from another different homecage, and placed into the remaining empty enclosure. To measure social memory, a delay of $1 \mathrm{~min}, 10 \mathrm{~min}, 1 \mathrm{~h}, 2 \mathrm{~h}$, or $24 \mathrm{~h}$ between the end of sociability and beginning of social novelty sessions was imposed. During the delay period, the test subject and Stranger 1 were separated and returned to their own homecages (Nadler et al., 2004; Riedel et al., 2009).
The measures of total occupancy time, active time, and traveling distance in each virtual zone were automatically quantified by the SmartCage (Khroyan et al., 2012). The enclosures occupied areas of the homecage that were designated as zones 1 and 3 (zones 1 and 3 were of equal size, whereas the middle zone, zone 2 , was twice the size, representing the neutral open area between the two enclosures). All three parameters reflect the same social interaction patterns, but occupancy time is the most sensitive and robust quantification, consistent with the conventional "three-chamber" apparatus test (Crawley, 2004; Nadler et al., 2004).

Nasal administration of Hcrt-1 to mice. The AT and WT mice were nasally dosed with Hcrt-1 (Orexin-A) following the Frey method of nasal administration in rodents (Hanson and Frey, 2008). Mice were individually placed in a supine position while under isoflurane anesthesia within a nose cone. A roll of gauze pad was inserted under the dorsal neck to extend the head back toward the supporting surface. The upper surface of the neck was kept horizontal throughout the dosing procedure to maintain the drug solution in the nasal cavity and to minimize dripping down the nasopharynx. A $2 \mu \mathrm{l}$ drop of either Hcrt-1 or deionized water was delivered off of the tip of a small pipette and presented to one side of the nares while occluding the opposite naris. One drop of solution was administered every $2 \mathrm{~min}$, alternating between each naris. After each nasal application, the mouse was returned to the nose cone to ensure maintenance of anesthesia. Each naris received 2 drops of solution, totaling a combined volume of $8 \mu \mathrm{l}$ of Hcrt- $1(0.8 \mathrm{nmol} /$ mouse, $n=14 \mathrm{AT}$ and $n=$ $14 \mathrm{WT})$ or deionized water $(n=13 \mathrm{AT}, n=14 \mathrm{WT})$. After completion of the administration, the mice were removed from anesthesia and allowed to regain full consciousness in a fresh homecage. Thirty minutes after nasal application, each mouse was subjected to the social memory test with a 10 or 120 min delay between sociability and social novelty testing sessions, as described above.

Direct contact social behavioral test. Procedures described previously (Thor and Holloway, 1986; Kogan et al., 2000) were adapted for this study. Individual test subjects were placed into fresh mouse homecages in an observation room under dim light and allowed to habituate to the new environment for $15 \mathrm{~min}$. A stimulus mouse (same sex and similar age as the test subject) taken from a different homecage was introduced into the cage with the test subject as a social cue for an initial interaction trial of 5 $\mathrm{min}$. The intervals between the initial trial and social memory test were 30 $\min , 3 \mathrm{~h}$, or $24 \mathrm{~h}$ as specified in the figure legends. After the selected separation period, the test subject was returned to the test cage with either the familiar or a novel stimulus mouse for the 5 min recognition test. The experimenter manually scored the time that the test subject spent investigating the social cue. Investigation behaviors include contact with any part of the stimulus mouse's body surface by sniffing, grooming, licking, or pawing and close following (within $1 \mathrm{~cm}$ ) according to published procedures (Thor and Holloway, 1986; Kogan et al., 2000).

Olfactory habituation/dishabituation test. The ability to detect odors and discriminate between odors was assessed as described previously (Yang and Crawley, 2009). The test mouse was placed into a fresh homecage with a clean metal rack. A clean, dry cotton-tipped wooden applicator (Medline) was inserted through the water bottle hole of the metal rack and fixed in place. Olfactory testing for nonsocial odors was in the following sequence: (1) distilled water, (2) almond extract fresh solution (1:100 dilution; Vanns Spices), and (3) banana extract fresh solution (1:100 dilution; Vanns Spices). Olfactory testing for social odors was done by swiping the applicator in a mouse cage unfamiliar to the test mouse. Each odor was exposed three times consecutively. The experimenter manually scored the cumulative time spent sniffing the tip during the 2 min trial.

Acoustic startle and prepulse inhibition experiments. Acoustic startle and prepulse inhibition were conducted using the SR-Lab startle response system (San Diego Instruments) following a procedure described previously (Geyer and Dulawa, 2003). Mice were placed in a Plexiglas cylinder resting on the sensor platform within a sound-attenuated and ventilated chamber. Acoustic startle stimuli, prepulse stimuli, and continuous background white noise of $65 \mathrm{~dB}$ were delivered via a highfrequency speaker. After an acclimation period of $5 \mathrm{~min}$ in the containment cylinder, mice were exposed to startle stimuli at five inten- 

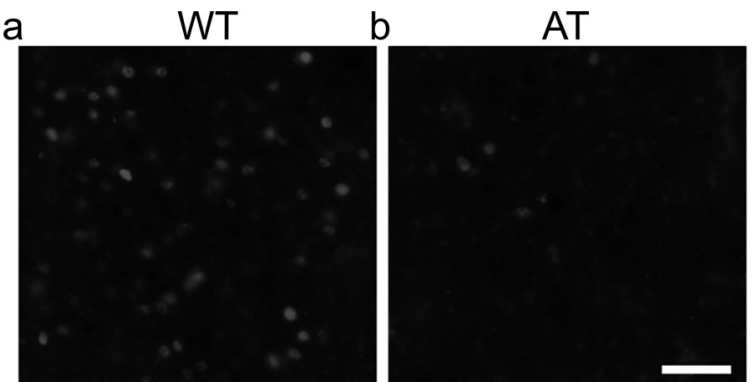

C

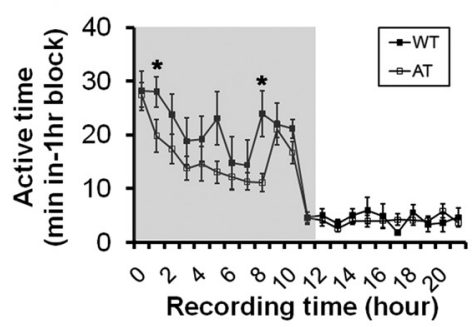

d

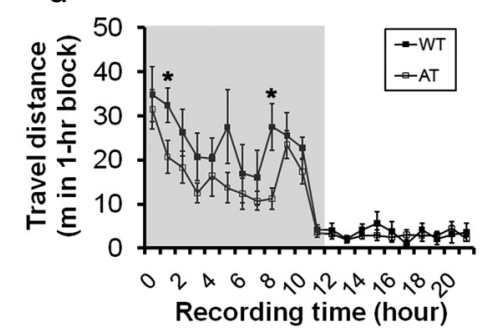

$f$

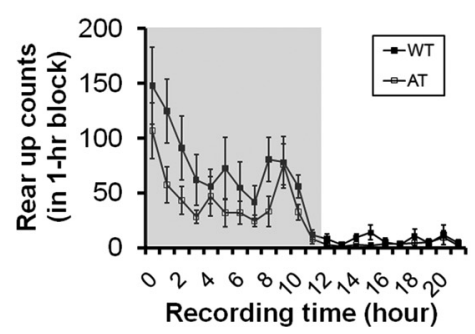

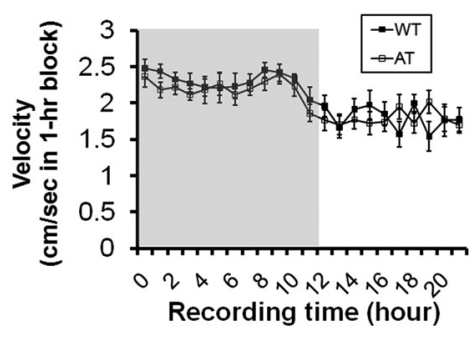

Figure 1. Comparison of Hcrt-positive neurons and spontaneous homecage activity between AT mice and their WT littermates. Representative images of immunofluorescent staining of the lateral hypothalamus taken from WT mice $(\boldsymbol{a})$ and AT mice $(\boldsymbol{b})$ at 3 months of age are shown. Scale bar, $100 \mu \mathrm{m}$ in $\boldsymbol{b}$ applied to $\boldsymbol{a}$. Shown is a comparison of active time (c, recording hour $1,{ }^{*} p=$ 0.048 , and recording hour $8, p=0.015)$, traveling distance $\left(d\right.$, recording hour $1,{ }^{*} p=0.025$, and recording hour $8, p=0.014$ ), rearing activity $(\boldsymbol{e})$, and traveling speed $(\boldsymbol{f})$ in AT and WT littermates in a $24 \mathrm{~h}$ record using the SmartCage system. Gray background in figures $\boldsymbol{c}-\boldsymbol{f}$ indicates dark phase during a 12:12 light:dark cycle (lights on at 7:00 A.M.; lights off at 7:00 P.M.). Data shown are mean \pm SEM for each time point ( $1 \mathrm{~h}$ bin). Subjects were 5 -month-old male mice $(n=8 /$ genotype).

sities $(80,90,100,110,120 \mathrm{~dB})$ and each startle reflex amplitude was recorded. Each prepulse inhibition trial consisted of a startle stimulus $(120 \mathrm{~dB}, 40 \mathrm{~ms})$, which was preceded by a prepulse $(70-90 \mathrm{~dB}, 20 \mathrm{~ms})$ with a fixed interval $(100 \mathrm{~ms})$ between onset of the prepulse and startle stimuli. Each trial was conducted once in a pseudorandom sequence with a variable intertrial interval of $12-30 \mathrm{~s}$.

Hippocampal slice preparations and extracellular recordings. Hippocampal brain slices ( $400 \mu \mathrm{m}$ thick) were prepared using a tissue slicer (Stoelting) as described previously (Xie and Smart, 1994) and incubated in artificial CSF (ACSF) that was oxygenated with $5 \% \mathrm{CO}_{2} / 95 \% \mathrm{O}_{2}$. The ACSF contained the following (in mM): $\mathrm{NaCl} 124.0, \mathrm{KCl} 2.5, \mathrm{KH}_{2} \mathrm{PO}_{4}$ $1.2, \mathrm{CaCl}_{2} 2.4, \mathrm{MgSO}_{4} 1.3, \mathrm{NaHCO}_{3} 26.0$, and glucose 10.0. All electrophysiological recordings were made $1-6 \mathrm{~h}$ after dissection.

Extracellular recordings were performed at room temperature using an AxoClamp2B amplifier and pClamp 10.3 software (Molecular Devices). Field EPSP (fEPSP) in Schaffer collateral-CA1 synapses was recorded using a glass microelectrode filled with the ACSF. Biphasic current pulses $(0.2 \mathrm{~ms})$ were delivered through a concentric bipolar stimulating electrode (FHC). Both recording and stimulus electrodes were placed in parallel on stratum radiatum separated by $\sim 500 \mu \mathrm{m}$ to record fEPSP evoked by stimulation of the Schaffer collateral and commissural fibers. Data were collected using DigiData 1332 and analyzed with Clampfit (Molecular Devices). Input-output (I-O) curves were obtained using stimulus intensity from the threshold to a strength evoking the maximum response. The fEPSP slope was measured from the initial phase of the negative wave. The I-O curve was constructed by plotting the
fEPSP slope against the fiber volley amplitude. The fiber volley amplitude was binned at 0.2 $\mathrm{mV}$ across slices for clarity of presentation. For the basal synaptic activity, test pulse intensities were adjusted to $30-35 \%$ of the maximal stimulation intensity and delivered at $10 \mathrm{~s}$ intervals. The PPF was induced by a pair of stimulations at intervals of 20,50 , or $100 \mathrm{~ms}$. Highfrequency stimulation (HFS) consisted of 4 trains of 100 pulses ( $0.2 \mathrm{~ms}$ pulse duration, 100 $\mathrm{Hz}$ ) with an intertrain interval of $20 \mathrm{~s}$. LTP was plotted as the percentage changes in the fEPSP slope after HFS relative to the basal slope of 5 averaged consecutive fEPSP (mean \pm SEM) just before HFS.

Measurement of CREB and $p C R E B$. Proteins were extracted from fresh hippocampi taken from the AT and WT littermates after the social interaction tests. Total CREB and PCREB were detected using antibodies \#9197S and \#9198S, respectively (Cell Signaling Technology) as described previously (Tardito et al., 2009). $\beta$-actin was obtained from Sigma. In each lane, $30 \mu \mathrm{g}$ of protein was subjected to SDS-PAGE using 4-15\% Ready Gel (Bio-Rad) for $1.5 \mathrm{~h}$. Protein bands were transferred from the gel to PVDF membranes (Millipore) for $1 \mathrm{~h}$. After the membrane was blocked with $5 \%$ nonfat dry milk (Bio-Rad) in PBS/0.05\% Tween 20, primary antibodies were incubated overnight at $4^{\circ} \mathrm{C}$, followed by exposure to horseradishperoxidase-conjugated secondary antibody ( 1 : 2000; Cell Signaling Technology) for $1 \mathrm{~h}$. The membrane was then incubated with anti- $\beta$ actin antibodies (1:10,000; Sigma) as an evenloading control of total protein. Membranes were scanned using the Typhoon trio (GE Healthcare). Optical densities of CREB and pCREB were analyzed from Western blots with normalization to $\beta$-actin.

Data analysis. The experiments were performed with genotypes and treatments blinded to the experimenters. All data are presented as mean \pm SEM and were subjected to statistical tests with two tails. For two groups, paired or unpaired Student's $t$ tests were used, as appropriate. Multiple-group comparisons were analyzed using two-way repeated measures ANOVA with drug or genotype as the between-genotype variable and time interval as the repeated measure. If the ANOVA was statistically significant, Fisher's PLSD was used to determine group differences. Data from the two components of the social behavior test (sociability and social novelty) were analyzed using within genotype repeated-measures ANOVA, with the factor of cage side (e.g., zone 1 vs 3 ). The difference was considered significant when $p<0.05$.

\section{Results}

AT mice display normal sociability in the two-enclosure homecage test

Compared with their WT littermates, AT transgenic mice had substantial Hcrt-positive cell loss (Fig. 1a,b) and exhibited significantly lower spontaneous activity as indicated by active time (Fig. $1 c$; ANOVA, $F_{(1,14)} p=0.040$, Fisher's PLSD at recording hour $1, p=0.048$, and at hour $8, p=0.015$ ), and distance traveled (Fig. $1 d$, hour $1, p=0.025$, and hour $8, p=0.014$ ). However, AT mice did not show significant differences in rearing (Fig. 1e) or traveling speed (Fig. $1 f$ ) in the dark phase measured using the SmartCage (Fig. $1 c-f$ ), which is consistent with the previously reported phenotype (Hara et al., 2001). We used the validated 
a

Sociability

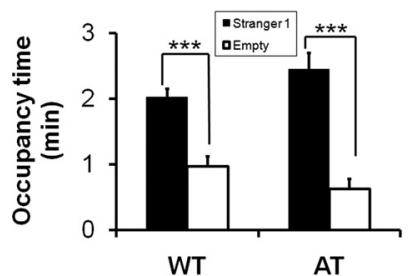

C Social memory 60 min delay

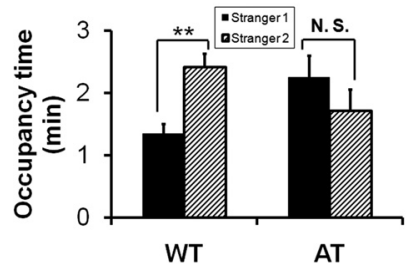

d WT: Sociability

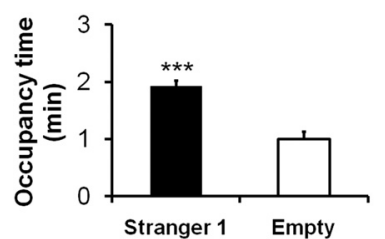

b Social novelty

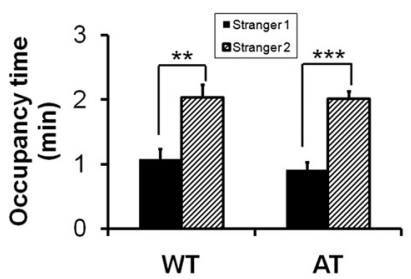

1 min delay

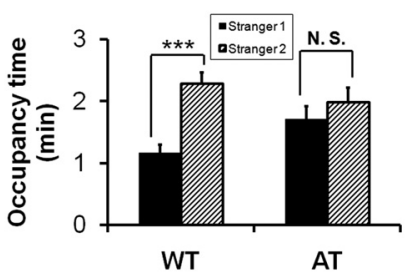

e WT: Social memory (24-h delay)

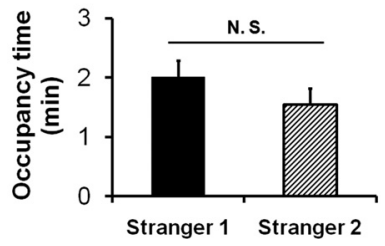

Figure 2. Comparisons of sociability, social novelty, and social recognition memory in AT mice and their WT littermates conducted during the light phase. $\boldsymbol{a}$, The test AT mice displayed normal sociability similar to WT mice. $\boldsymbol{b}$, AT mice displayed a normal degree of preference to a novel mouse (social novelty) compared with WT littermates when there was no delay between the end of the sociability session and the initiation of social novelty test. $c$, In two separate cohorts of animals, both genotypes exhibited normal sociability with Stranger 1 (data not shown). Stranger 2 was introduced 1 or $60 \mathrm{~min}$ after the sociability session. AT mice displayed deficits in social memory after a delay of $60 \mathrm{~min}$ (left) and $1 \mathrm{~min}$ (right), whereas WT mice displayed social memory in both delay time points. $\boldsymbol{d}$, WT mice exhibited normal sociability toward Stranger 1.e, The same cohort of WT mice lost preference for social novelty after a $24 \mathrm{~h}$ delay to reexpose the same Stranger 1 and a novel Stranger 2. Data are shown as mean \pm SEM. $\boldsymbol{a}$ - $\boldsymbol{c}$ are the same cohorts of test mice, 3 -month-old males ( $n=8$ per group); $\boldsymbol{d}$ and $\boldsymbol{e}$ are the same cohort of test WT 3-month-old males $(n=8)$. Paired Student's $t$ test within genotype: ${ }^{*} p<0.05 ;{ }^{* *} p<0.01 ;{ }^{* * *} p<0.001$.

two-enclosure homecage testing procedure and quantified mouse behavior using the automated SmartCage system (Khroyan et al., 2012). Under these conditions, the test subject freely explored the fresh homecage with nonsocial cues (i.e., identical empty enclosures) or social cues (i.e., stranger mice that were taken from different homecages). During habituation, most test mice (AT and WT) spent an equal amount of time in zones 1 and 3, indicating an equal amount of interest or no bias toward either nonsocial cue. During the sociability session, all test mice spent significantly more time investigating Stranger 1 compared with the nonsocial cue (i.e., empty enclosure, Fig. 2a,b; paired Student's $t$ test within genotype, WT: $t_{(7)}=4.47, p=0.003$; AT: $\left.t_{(7)}=5.59, p=0.001\right)$. During the social novelty test without a delay between the completion of sociability and the initiation of the social novelty sessions, all test subjects spent more time investigating Stranger 2 than the familiarized Stranger 1 (Fig. $2 b$; WT: $t_{(7)}=4.3, p=0.003$; AT: $\left.t_{(7)}=5.217, p=0.001\right)$. Analysis of two other parameters, active time and travel distance, in zones 1 and 3 yielded similar social interaction patterns (data not shown). These results

indicate that there are no significant differences in sociability and social novelty between the genotypes.

\section{AT mice display deficits in long-term social memory}

We next tested the hypothesis that Hcrt neurons play a role in social recognition retention or memory. It has been shown that a delay in the social novelty test reduces the test subject's preference to social novelty (Nadler et al., 2004; Riedel et al., 2009). We started with a $60 \mathrm{~min}$ delay and then reduced to a 10 or $1 \mathrm{~min}$ delay. With a delay as short as $1 \mathrm{~min}$, the AT subjects did not shift their investigation to Stranger 2 over the familiarized Stranger 1; rather, they spent an indistinguishable amount of time investigating the familiar and novel social cues (Fig. 2c). In contrast, WT subjects shifted their investigation to Stranger 2 after a 10 or 60 min delay (Fig. $2 c$ ). In a separate experiment using new cohorts of WT mice, although these mice displayed typical sociability with a delay of 24 , the test subjects failed to show preference for novel social cues, indicating that normal recognition retention does not extend beyond $24 \mathrm{~h}$ in this indirect social test (Fig. $2 d, e$ ).

A previous study reported that Hcrt knock-out mice were unable to work for food or water reward during the light phase, but performed normally during the dark phase, suggesting a specific role of Hcrt neurons in the diurnal phase (McGregor et al., 2011). We therefore investigated whether the deficit in long-term social memory observed in AT mice could be due to a reduction in arousal or alertness levels during the circadian light phase. Separate cohorts of AT and WT littermates were tested for their social interaction and memory in the first $3 \mathrm{~h}$ of the dark phase using the same 2-enclosure homecage test. As in the light phase, AT mice and their WT littermates displayed normal sociability and social novelty when there was no delay (Fig. $3 a, b$ ). However, AT mice retained short-term social memory after a 1 min delay (Fig. 3f; paired Student's $t$ test, $t_{(7)}=2.80, p=0.03$ ), which was not observed when the same experiment was conducted in the light phase, suggesting that social memory formation is influenced by the arousal state (compare Fig. 3f, Fig. 2c). However, AT mice still exhibited a loss of social memory after a 10 min delay, whereas WT mice preserved their memory after a $10 \mathrm{~min}$ (Fig. $3 c-f$ ) and $1 \mathrm{~h}$ delay (data not shown) as tested in the light phase. WT mice failed to show preference for novel social cues after a delay of $2 \mathrm{~h}$ (Fig. 3e), indicating that WT mice did not dramatically improve social memory tested with this delay time point during the dark phase.

\section{Nasal administration of Hcrt-1 improves social memory in AT mice}

To test our hypothesis that a supplement of exogenous Hcrt in the brain of AT mice can lead to an overall improvement in social memory, AT mice were treated with Hcrt-1 via nasal administration, a method that has been shown to deliver a variety of peptides effectively into the brains of rodents (Hanson and Frey, 2008). Thirty minutes after nasal administration of either vehicle, deionized water $(n=13)$ or Hcrt-1 $(0.8 \mathrm{nmol}, n=14)$, the AT mice were subjected to the sociability test followed by a $10 \mathrm{~min}$ delay social memory test. The AT mice that were treated with vehicle spent significantly more time investigating Stranger 1 than the empty enclosure, indicating normal sociability. However, these mice did not shift their investigation to Stranger 2 over the familiarized Stranger 1 in a social memory test with a 10 min delay (Fig. $4 a$; ANOVA, $F_{(3,52)}=7.247, p<0.004$; Fisher's PLSD for sociability, $p<0.001$, and for social memory, $p=0.362$ ). In contrast, the AT subjects that were treated with Hcrt-1 displayed not only 


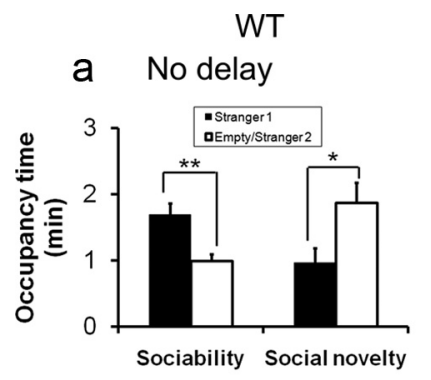

C 10 min delay

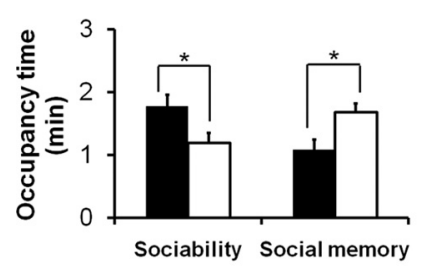

e 120 min delay

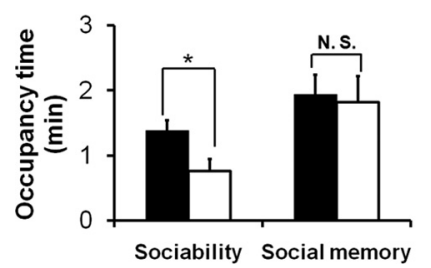

AT

b No delay

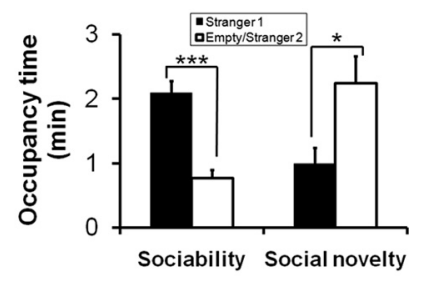

d 10 min delay

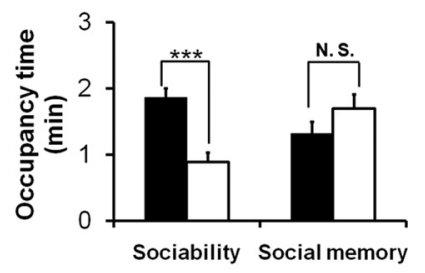

f 1 min delay

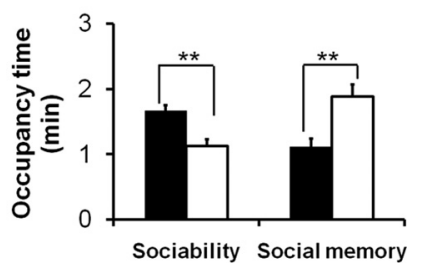

Figure 3. Comparisons of social memory between AT mice and their WT littermates conducted during the first $3 \mathrm{~h}$ of the dark phase. $\boldsymbol{a}, \boldsymbol{b}$, Both WT and AT mice displayed normal sociability and social novelty without a delay between the two test sessions. c, WT mice displayed social recognition when the delay between sociability and social novelty tests was 10 min.d, AT mice displayed deficits in social memory with a delay of 10 min.e, WT mice displayed a loss of social memory with a delay of 120 min. $f$, AT mice displayed short-term social memory with a delay of 1 min. Data are mean \pm SEM. Subjects were 3- to 6-month-old male mice $(n=$ $8-12$ /group). Paired Student's $t$ test: ${ }^{*} p<0.05 ;{ }^{* *} p<0.01 ;{ }^{* * *} p<0.001$.

normal sociability, but also a distinct shift in their investigation to Stranger 2 from familiarized Stranger 1 (Fig. $4 b$; ANOVA, $F_{(3,48)}=28.7, p<0.001$; Fisher's PLSD for sociability, $p<0.001$, and for social memory, $p<0.001)$. In addition to occupancy time, two other measureable social interaction parameters, active time $(p<0.001)$ and travel distance $(p=0.013)$, also indicated that the Hcrt-treated AT mice showed improvement in social recognition memory (Fig. $4 c-f$ ). Interestingly, Hcrt-1-treated WT mice did not produce a significant increase in social memory as tested with a 120 min delay compared with nasal vehicle treatment (data not shown) or nonnasal treatment (Fig. 2e).

\section{AT mice display normal social approach behavior but social memory deficit in direct contact social test}

To confirm the normal sociability of AT mice, we performed a direct contact social test with manual scoring of the test subject's interaction with a stimulus mouse taken from a different homecage acting as a social cue. The onset and duration of social interaction was indistinguishable between AT and WT littermates in the initial trial, confirming that both genotypes have normal sociability $(61.0 \pm 4.5 \mathrm{~s}$ in AT vs $62.1 \pm 6.7 \mathrm{~s}$ in WT, $n=$ 8/group, unpaired Student's $t$ test, $t_{(12)}=14, p>0.05$; Fig. $5 a, b$ ).

To verify deficits in the social memory of AT mice, the test subjects were exposed repeatedly to the same initial social cue with varying separation periods. Previous studies have suggested that the test subject's investigation time in the initial trial reflects
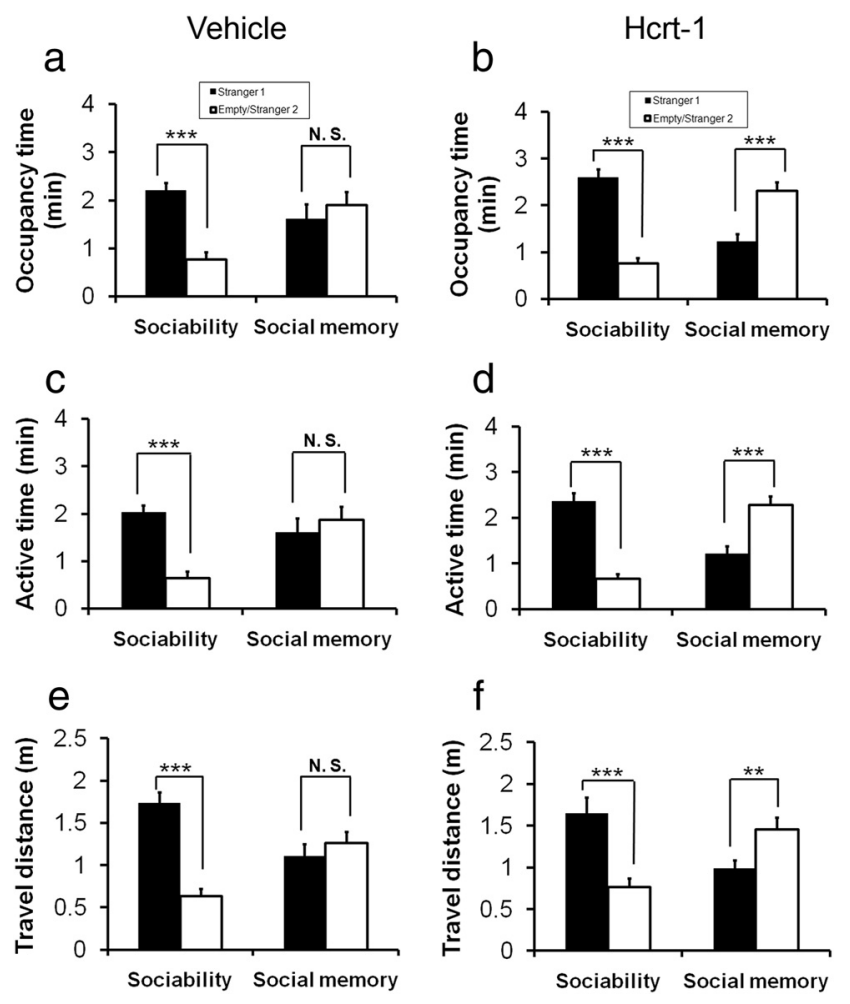

Figure 4. Nasal administration of Hcrt-1 improves social memory in AT mice. The AT subject mice received nasal administration of either vehicle (deionized water, $n=13, \boldsymbol{a})$ or Hcrt-1 ( 0.8 $\mathrm{nmol}, n=14, \boldsymbol{b})$. The social memory test with a 10 min delay between the completion of sociability and the beginning of social novelty sessions. The AT mice that were treated with vehicle exhibited normal sociability and reproducible social memory deficits ( $a$ : for sociability, $p<0.001$; for social memory, $p=0.362$ ). The AT subjects that were treated with Hert-1 displayed normal sociability, but also showed a distinct shift in their investigation to Stranger 2 from familiarized Stranger 1 ( $b$ : for sociability, $p<0.001$; for social memory, $p<0.001$ ). Other two measureable social interaction parameters, active time ( $c$ and $\boldsymbol{d}, p<0.001$ ) and travel distance ( $\boldsymbol{e}$ and $\boldsymbol{f}, p=0.013$ ), also indicated that the Hcrt-treated AT mice improved social recognition memory.

sociability, whereas a reduction in investigation time during the second exposure to the same social cue is correlated with social recognition retention (Thor and Holloway, 1986; Kogan et al., 2000 ). In the initial exposure, the test subjects spent $\sim 62.1 \pm 6.7 \mathrm{~s}$ investigating the social cue, as described above (Fig. 5a). In the second exposure to the same social cue, after a separation period of $24 \mathrm{~h}, 3 \mathrm{~h}$, or $30 \mathrm{~min}$, the WT test subjects decreased their investigation time toward the same social cue as the separation time reduced. The WT mice could at least recognize and remember the familiarized social cue after separation of up to $3 \mathrm{~h}$ (and not beyond $24 \mathrm{~h}$ ), as indicated by a significant decrease in investigation time compared with the initial trial (Fig. $5 a$; paired Student's $t$ test, at $30 \min t_{(6)}=6.17, p<0.001$, and at $3 \mathrm{~h} t_{(9)}=2.98$, $p<0.05)$. In contrast, the AT test subjects displayed decreased investigation time toward the familiarized social cue when the separation period was $30 \mathrm{~min}\left(t_{(6)}=6.16, p<0.001\right)$, but the AT mice did not reduce their investigation time after a $3 \mathrm{~h}$ delay $\left(t_{(7)}=-1.25, p>0.05\right.$; Fig. $\left.5 b\right)$, which confirms that they had a shorter recognition retention time compared with WT mice.

To eliminate the possibility that decreased investigation time in repeated trials was due to a decrease in interest/motivation of social interaction or locomotor activity, which could confound social memory readout, we tested social recognition retention with different stimulus mice between the initial trial and the second test. As shown in Figure $5 c$, both genotypes showed investi- 

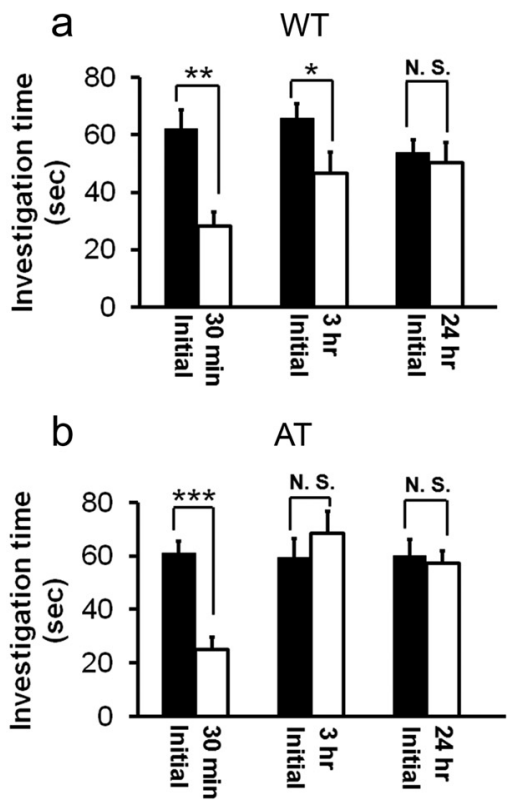

C

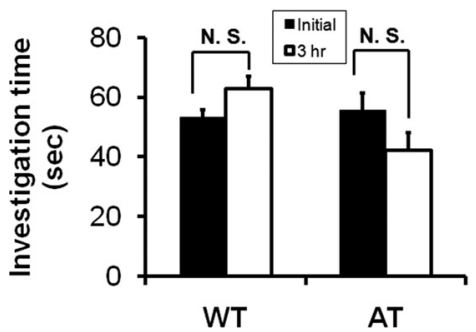

Figure 5. AT mice showed normal social interaction but with a social memory deficit compared with WT littermates in a direct contact social test. $\boldsymbol{a}$, Test WT mice displayed social approach behavior toward the stimulus mouse (sociability) and reduced the approach behavior toward the reexposed social cue mouse $30 \mathrm{~min}$ and $3 \mathrm{~h}$ after initial contact as measured by a reduction in investigation time ( $n=8$ per genotype). Paired Student's ttest: ${ }^{*} p<0.05 ;{ }^{* *} p<$ 0.01 . After a $24 \mathrm{~h}$ delay after the initial interaction, the test mouse spent the same amount of time investigating the same social cue mouse as in the initial trial. $\boldsymbol{b}$, Test AT mice displayed social approach behavior toward the stimulus mouse (sociability) and reduced investigation time toward the same social cue $30 \mathrm{~min}$ after the initial interaction ( $n=8$ per genotype). Paired Student's t test: ${ }^{*} p<0.05 ;{ }^{* *} p<0.01$. After a delay of 3 or $24 \mathrm{~h}$ after the initial interaction, the test mouse spent a similar amount of time investigating the reexposed social cue as in the initial interaction. $c$, AT and WT mice show similar investigation times toward two different, unfamiliar social cue mice between the initial trial and a second test after a $3 \mathrm{~h}$ delay. In the initial contact, the test subject displayed social approach behavior, as indicated by time investigating the stranger mouse. Three hours later, the same test subject was tested for its sociability toward a novel mouse (taken from another homecage). Subjects were 3-month-old male mice $(n=$ $8 /$ genotype). Paired Student's $t$ test, $p>0.05$ ).

gation time toward novel mice in a $3 \mathrm{~h}$ repeated test comparable to the initial trial, suggesting that social interaction interest/motivation remained the same as in the initial trial.

Olfaction plays an important role in social recognition in rodents, because chemically induced anosmia or removal of the vomeronasal organ blocks individual recognition (Ryan et al., 2008). In addition, soiled bedding samples from an unfamiliar mouse homecage can be used as cues in the recognition process. Therefore, we used the standard protocol for olfactory habituation/dishabituation ability tests (Yang and Crawley, 2009). Time spent sniffing a sequence of novel nonsocial (i.e., water, almond, and banana) and social odors (i.e., unfamiliar mouse cage odor) contained in cotton swab tips by the test subjects was scored manually. The result indicates that with the exception of the first

\section{a Olfactory habituation/dishabituation ability}
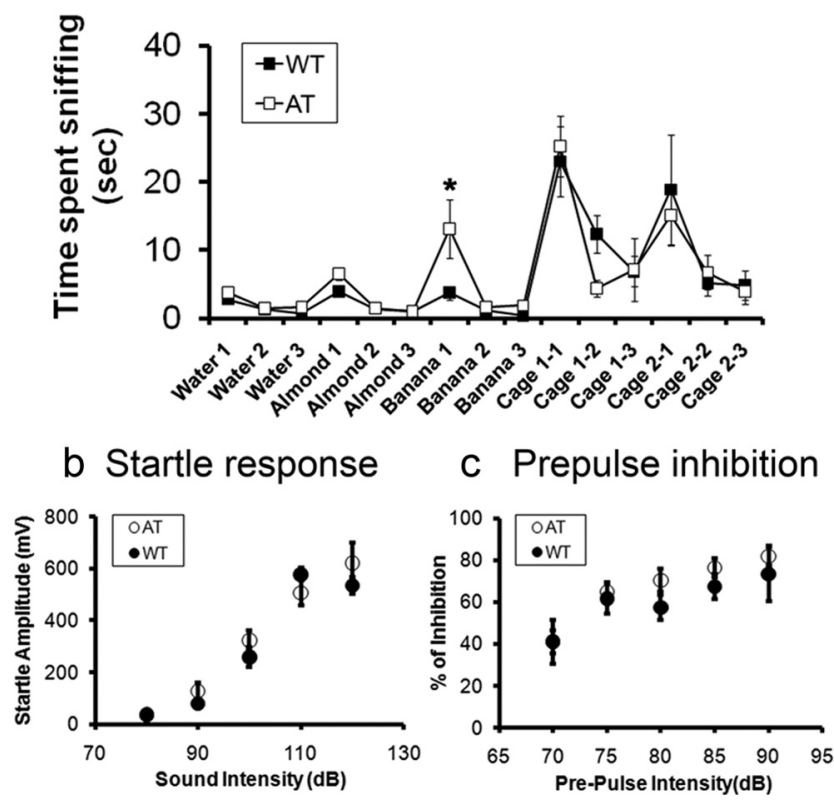

Figure 6. Comparison of olfactory and auditory reflex functions in AT mice and their WT littermates. $\boldsymbol{a}$, Olfactory habituation/dishabituation ability was measured as time spent sniffing a sequence of novel nonsocial (i.e., water, almond, and banana) and social odors (i.e., unfamiliar mouse cage odor) contained in cotton swab tips. Except for banana 1 (unpaired Student's $t$ test, $\left.{ }^{*} p<0.05\right)$, all data points were not significantly different between genotypes. $\boldsymbol{b}$, Startle responses evoked by different sound intensities $(80-120 \mathrm{~dB})$. There were no significant differences between the genotypes ( $n=8$ per group). $c$, Prepulse inhibition induced by a constant startle stimulus ( $120 \mathrm{~dB}, 40 \mathrm{~ms})$, which was preceded by a prepulse $(70-90 \mathrm{~dB}, 20 \mathrm{~ms})$ with an interval (100 ms) between the prepulse and startle stimuli. There were no significant differences between the genotypes. Subjects were 3- to 4-month-old male mice ( $n=8 /$ genotype).

banana exposure (unpaired Student's $t$ test, $t_{(14)}=-2.12, p<$ $0.05)$, all data points were not significantly different between the genotypes $(p>0.05)$. Furthermore, the olfactory habituation/ dishabituation patterns were almost identical to the published data (Yang and Crawley, 2009). Therefore, we conclude that deficits in social memory in AT mice were not caused by differences in olfactory discrimination ability (Fig. 6a).

Alternatively, auditory ability differences between AT and WT mice could also influence social interaction. To eliminate this possibility, we assessed acoustic startle responses evoked by a series of sound intensities (80-120 dB with an increment of 10 $\mathrm{dB})$. There were no significant differences in startle responses (Fig. $6 b$ ) or in prepulse inhibition between the two genotypes under our experimental conditions (Fig. 6c).

AT mice display deficits in hippocampal synaptic plasticity Because social recognition memory is dependent on hippocampal long-term synaptic plasticity (Kogan et al., 2000), we studied hippocampal synaptic basal activity and plasticity in the CA1 area using extracellular recording techniques as described previously (Xie and Smart, 1994). We first investigated basal synaptic transmission by analyzing the I-O relationships of fEPSPs evoked by various stimulus intensities. There were no significant differences in the I-O curves between AT and WT mice, indicating that AT mice have normal basal synaptic transmission and synaptic coupling efficiency in the Schaffer collateral-CA1 synapses (Fig. 7a).

We next analyzed PPF, a presynaptic form of short-term synaptic plasticity, using intervals of 20,50, and $100 \mathrm{~ms}$ between a pair of stimulation pulses. All three paired pulses of different 


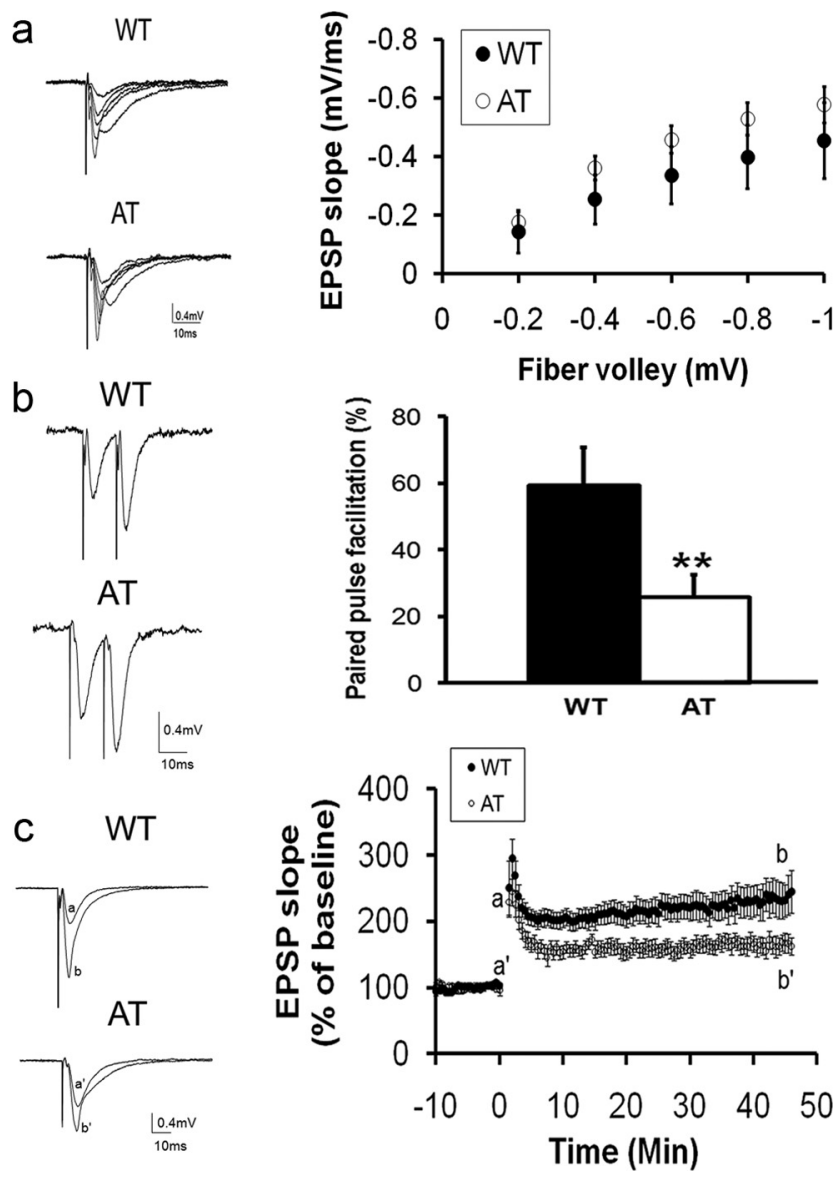

Figure 7. AT mice exhibited normal basal synaptic neurotransmission but a decreased PPF ratio and attenuated LTP in the CA1 area of hippocampal slices compared with WT littermates. $\boldsymbol{a}$, Left, A family of representative voltage traces of fEPSPs in the CA1 area of WT or AT hippocampal slices evoked by different stimulation intensities on the Schaffer collateral and commissural fibers. Right, $\mathrm{I}-0$ of the fEPSP. The fiber valley was binned with an interval of $0.2 \mathrm{mV}$. There were no significant differences in the I- 0 curves between the genotypes (WT: $n=14$ slices from 5 mice; $A T: n=14$ slices from 6 mice). $\boldsymbol{b}$, Comparison of PPF ratio between AT and WT littermates. Left: Representative traces of paired pulse stimulation with $20 \mathrm{~ms}$ interval from WT and AT littermates, respectively. Right, The PPF ratio is significantly higher in WT mice than AT mice (WT: $59.3 \pm 11.3 \%, n=12$ slices from 5 mice; AT: $25.7 \pm 6.9 \%, n=14$ slices from 6 mice; unpaired Student's $t$ test, $p=0.02$ ). $c$, AT mice exhibited decreases in the amplitude of LTP in the CA1 area of hippocampal slices compared with WT littermates. Left, Representative voltage traces of fEPSP are superimposed before (a) and after (b) LTP induction by high-frequency stimulation of the Schaffer collateral and commissural fibers $(100 \mathrm{~Hz}, 1 \mathrm{~s}, 4$ trails, 20 s interval). Right, Each fEPSP slope was normalized to that just before the high-frequency stimulation and plotted as a function of recording time. The magnitude of LTP during the maintenance phase in WT slices is significantly larger than that in AT slices (WT: 234.6 $\pm 23.8 \%, n=14$ slices from 5 mice; AT: $164.3 \pm 12.7 \%, n=14$ slices from 6 mice; 2 -tailed unpaired Student's $t$ test, $p=0.02$ ).

intervals induced facilitation of fEPSP in both WT and AT mice. The degree of all PPFs was reduced in AT mice, but reached a significant level only with the shortest interval $(20 \mathrm{~ms})$. Figure $7 b$ shows that with a $20 \mathrm{~ms}$ stimulus interval, the slope of the second fEPSP in WT mice was $59.3 \pm 11.3 \%$ higher than that of the first fEPSP ( $n=12$ slices from 5 mice), whereas the slope of the second fEPSP in AT mice was $25.7 \pm 6.9 \%$ higher than that of the first fEPSP in AT mice ( $n=14$ slices from 6 mice). The $20 \mathrm{~ms}$ interval-induced PPF in WT brain slices was significantly higher than in AT slices (unpaired Student's $t$ test, $t_{(24)}=-2.63, p=$ 0.02 ). The slope of the first fEPSP in WT and AT mice was $0.15 \pm$ 0.02 and $0.19 \pm 0.02 \mathrm{mV} / \mathrm{ms}$, respectively. These results again indicate that the two genotypes had a similar level of basal syn- aptic activity level (unpaired Student's $t$ test, $t_{(24)}=-1.41, p=$ 0.18 ). Therefore, the smaller PPF in the AT mice was not caused by differences in basal synaptic strength.

To investigate the functional consequences of the loss of Hcrt neuronal input on long-term synaptic plasticity, we compared LTP in the CA1 area. The results indicated that the magnitude of the maintenance phase of LTP in WT mice was greater than that in AT mice (Fig. 7c). Analysis of the averaged five consecutive slopes of fEPSP in the CA1 in WT mice revealed an increase to $234.6 \pm 23.8 \%$ of the baseline level at $45 \mathrm{~min}$ after HFS ( $n=14$ slices from 5 mice). In AT mice, the slope of fEPSP in CA1 was $164.3 \pm 12.7 \%$ of baseline at the same time point $(n=14$ slices from 6 mice; unpaired Student's $t$ test, $t_{(24)}=-2.71, p=0.02$ ). These results indicate that synaptic plasticity in AT slices was impaired compared with WT mice. Before HFS, the basal level of fEPSP slopes for WT and AT mice was $-0.14 \pm 0.01$ and $-0.19 \pm 0.02 \mathrm{mV} / \mathrm{ms}$, respectively $\left(t_{(26)}=-1.87, p=0.07\right)$. Therefore, the smaller magnitude of LTP in AT mice was not due to differences in the basal level of fEPSP between genotypes (Fig. 7c).

\section{AT hippocampi have lower levels of pCREB}

Lastly, we explored possible signaling pathways related to hippocampal CA1 LTP and social memory in behavior. CREB is a nuclear protein that modulates the transcription of genes with cAMP-responsive elements in their promoters and acts as a universal modulator of processes required for memory formation, especially hippocampus-dependent social memory. Mice deficient in the $\alpha$ and $\Delta$ isoforms of the CREB transcription factor (CREBaD2 mice) are impaired in long-term, but not short-term, social memory (Bourtchuladze et al., 1994; Silva et al., 1998; Kogan et al., 2000). We therefore investigated the level of total CREB and pCREB, the active form of CREB in hippocampi, taken from mice after social interaction and memory testing $(n=9$ mice per genotype). In both genotypes, CREB immunostaining was found to be distributed heterogeneously in most cell bodies throughout the hippocampus (Fig. 8a). Immunostaining indicated that there were no significant differences in total CREB expression between the genotypes. However, the pCREB level was apparently lower in the hippocampus taken from AT compared with that of WT mice, although most neurons expressed pCREB in both genotypes (Fig. 8a). Optical density analysis on the Western blot from hippocampi from each genotype quantified the CREB and pCREB levels. The quantitative analyses obtained from the Western blots confirmed that there was no significant differences in total CREB expression between the genotypes and revealed that PCREB in the AT hippocampus was significantly lower by $25 \pm 7.5 \%$ compared with the WT hippocampus (Fig. $8 b ; n=9$ Western blot bands from nine mice of each genotype, unpaired Student's $t$ test, $t_{(16)}=2.29, p<0.05$ ).

\section{Discussion}

Social recognition memory, the ability to distinguish and remember familiar from novel conspecifics, is critical for appropriate social behavior. Rodents can retain recognition of recently encountered conspecifics for a certain period of time. In the present study, using AT mice in which Hcrt neurons are genetically ablated (Hara et al., 2001), we obtained the novel result that the endogenous Hcrt system is essential for the formation of longterm social memory. A recent microdialysis study of Hcrt in human brain revealed a dramatic increase in Hcrt levels associated with social interaction (Blouin et al., 2013). Our study supports this clinical observation and defines the physiological role of the 
Hcrt system in social memory, but not necessarily in the initiation of social approach, because AT mice displayed normal sociability. Our results suggest that the Hcrt surge upon interaction with conspecifics consolidates storage of information, but may not be critical in the stages of encoding (e.g., processing information) or retrieval (e.g., recalling) of stored information, because AT mice could process and recognize the familiarized social cue and displayed preference to the novel social cue when there was no delay or a short delay (e.g., $1 \mathrm{~min}$ ) in the memory test.

To assess social interaction in humans and animal models, several behavioral tests have been developed (KaidanovichBeilin et al., 2011). The three-chamber apparatus and testing procedure have been used commonly to assess rodents' sociability, social novelty, and social memory (Crawley, 2004; Moy et al., 2004; Deng et al., 2007). AT mice display decreased active time and locomotion, which could confound social behavior testing, especially when using a large, unfamiliar chamber with physical dividers. We therefore developed and validated a two-enclosure test in a mouse homecage (Khroyan et al., 2012), and showed the social interaction pattern to be comparable to the results obtained previously using the three-chamber test (Crawley, 2004; Moy et al., 2004; Deng et al., 2007). Using this objective testing method, we found that AT mice displayed normal sociability and social novelty, but exhibited a long-term memory deficit.

The social memory of AT mice was shorter than 1 min when the test was conducted in the light phase, but at least $1 \mathrm{~min}$ and shorter than 10 min when the task was performed in the dark phase. The improvement in social recognition task performance during the dark phase not only supports the finding of the specific role of Hcrt neurons in reward behavior during the diurnal phase (McGregor et al., 2011), but also suggests that the arousalpromoting role of Hcrt may be crucial in the consolidation of memory storage. Interestingly, the social memory of the WT mice was not enhanced at the time point tested in the dark phase, suggesting a possible "saturated effect" of Hcrt levels in WT mice. Alternatively, enhancement of social memory could be observed in refined delay time points.

Hcrt neurons also produce other neurotransmitters, such as dynorphin, pentraxin, and glutamate, which may influence memory (Chou et al., 2001; Reti et al., 2002; Rosin et al., 2003). Therefore, it is important to determine whether a supplement of exogenous Hcrt in the brain can restore long-term social memory in AT mice. Indeed, we found that nasally administered Hcrt-1 extended social memory in AT mice from $<1$ min to at least 10 min when tested in the light phase. In contrast, Hcrt-1 did not prolong social recognition retention in WT mice tested with a 120 min delay. These findings are compatible with previous results showing that nasal administration of Hcrt-1 selectively improves sleep-deprivation-caused memory deficits without enhancing memory in normal nonhuman primates (Deadwyler et al., 2007). However, these treatment regimens were acute and whether b

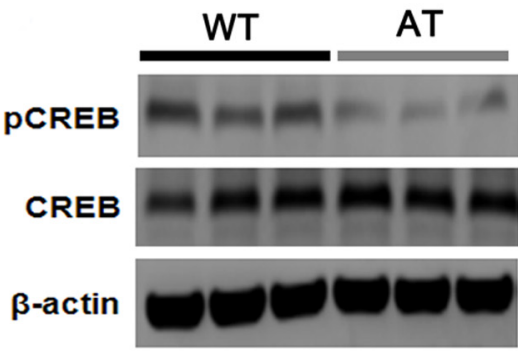

CREB
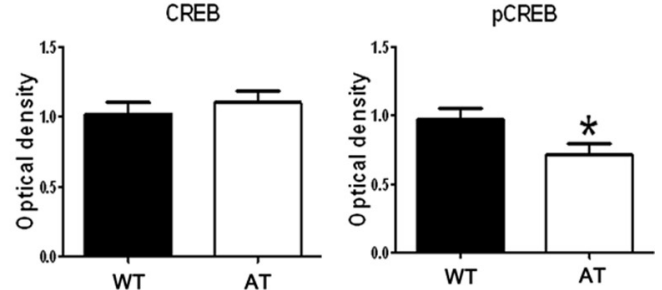

AT

WT

AT

AT

Figure 8. Levels of pCREB in hippocampi of AT mice is lower compared with those in WT hippocampi. $\boldsymbol{a}$, Representative images (the whole coronal section of the hippocampus taken from in the hippocampi taken from AT mice than that from WT littermates $(n=9$ Western blot bands from $n=9$ mice per genotype; 05). Optical densities of both CREB and pCREB were normalized to $\beta$-actin.

chronic treatment with Hcrt can enhance memory is worthy of further investigation.

The deficit in long-term social memory in AT mice was corroborated by a conventional direct contact social test. In this test, social recognition memory was inferred by a decrease in the investigation time toward the reexposed social cue (Thor and Holloway, 1986; Kogan et al., 2000). The direct contact allows more engagements between the test subject and the social cue, leading to stronger social stimulation, and therefore longer recognition retention, compared with the two-enclosure test. AT mice exhibited normal sociability toward unfamiliar conspecifics and their social recognition retention lasted at least $30 \mathrm{~min}$ but $<3 \mathrm{~h}$. In contrast, the WT mice's recognition retention lasted for at least $3 \mathrm{~h}$ and disappeared after $24 \mathrm{~h}$ of separation. The AT mice deficit in long-term memory was not due to any defects in olfactory or auditory ability, because there were no significant differences in the olfactory habituation/dishabituation patterns or acoustic startle responses and prepulse inhibition between the AT and WT littermates.

Social recognition, particularly long-term memory in humans and rodents, relies critically on intact hippocampal structure and function (Corkin et al., 1984; van Wimersma Greidanus and Maigret, 1996; Kogan et al., 2000). The hippocampus receives direct input from Hcrt neurons and expresses Hcrt receptors. Furthermore, Hcrt-mediated activation of noradrenergic and serotonergic systems might also play a role in consolidating memory, because these monoaminergic neurons project abundantly to the hippocampus (Peyron et al., 1998; Kilduff, 2005; Carter et al., 2009; Eriksson et al., 2010; de Lecea, 2010; Sakurai and Mieda, 2011). We therefore focused on the investigation of hippocampal synaptic plasticity and signaling pathway to explore mechanisms underlying the effects of Hcrt in the storage of social memory.

Although CA1 had normal basal neurotransmission in both AT mice and their WT littermates, both PPF and LTP were 
significantly attenuated in the AT hippocampi. These results suggest that short- and long-term synaptic plasticity in the AT hippocampus may be impaired in the absence of Hcrt neuronal input. Conversely, an LTP-like phenomenon in the CA1 area could be induced by the application of exogenous Hcrt-1 in hippocampal slices via activation of several protein kinases, including protein kinase A and C (Selbach et al., 2010). Moreover, Hcrt in the ventral tegmental area has been shown to be critical for the induction of synaptic plasticity that was associated with behavioral sensitization to cocaine in rats (Borgland et al., 2006).

The formation of long-term memory in hippocampusdependent cognitive tasks, including social recognition, has been found to involve CREB. CREB acts as memory storage and sustains synaptic plasticity in a wide range of synapses, including in the hippocampus. Several neurotransmitters, especially dopamine, serotonin, noradrenaline, and acetylcholine, all of which are known to enhance memory, induce CREB phosphorylation (Bourtchuladze et al., 1994; Silva et al., 1998; Kogan et al., 2000; Thonberg et al., 2002). The Hcrt system has been found to synapse directly and activate the amine systems and to promote noradrenaline and acetylcholine release (Carter et al., 2009; Eriksson et al., 2010; Stanley and Fadel, 2012). Complementary to this indirect "upstream" modulation of CREB, Hcrt can activate CREB directly by acting on Hcrt receptors that are Gq-proteincoupled receptors. This leads to signaling through phospholipase $\mathrm{C}$ and calcium-dependent and calcium-independent transduction pathways (Sakurai et al., 1998; Sakurai and Mieda, 2011). Activation of Hcrt receptors also leads to stimulation of protein kinase A and C, as mentioned above (Selbach et al., 2010), and a recent study showed that exogenous Hcrt prolonged CREB phosphorylation via protein kinase $\mathrm{C}$ activation (Guo and Feng, 2012). As shown in this study, the level of pCREB in WT hippocampi was significantly higher than in AT hippocampi, whereas there were no significant differences in total CREB between the genotypes.

Social memory underpins and enables appropriate social interaction, which is critical for the establishment of relationships and for the stability of the social networks. Several neuropsychiatric disorders are characterized by disruptions of social recognition or long-term social memory, including schizophrenia, bipolar disorders, depression, attention-deficit hyperactivity disorder, and autism spectrum disorders (McClure et al., 2003; Riedel et al., 2009; Brotman et al., 2010; Ibi et al., 2010; Kaidanovich-Beilin et al., 2011). Loss of Hcrt neurons causes narcolepsy in humans (Scammell et al., 2001; Siegel et al., 2001). Narcoleptic patients are often anxious about disease-related deficient memory functions (Aguirre et al., 1985; Rogers and Rosenberg, 1990) and modest memory impairments have been described previously (Henry et al., 1993; Naumann et al., 2006). Although narcoleptic patients display normal sociability, whether they have deficits in long-term social memory is currently unknown, and this can be a potential area for clinical investigation.

The present study has uncovered a physiological role of Hcrt neurons in long-term social memory using a transgenic animal model and pharmacological approach. Hcrt neurons apparently are not essential for sociability, but play a critical role in the formation of long-term social memory. This finding is consistent with the notion that the Hcrt system contributes to spatial and nonsocial learning and memory (Jaeger et al., 2002; Akbari et al., 2007; Eriksson et al., 2010; Fadel and Burk, 2010). The mechanisms underlying the effects of Hcrt in the formation of social memory is through, at least in part, enhancing synaptic plasticity and increasing pCREB in the hippocampus. The previously unrecognized role for the Hcrt system in social memory may have clinical implications and our study will foster further integrative research using animal disease models and appropriate tests to identify novel neuronal pathways and therapeutics for the modulation of social interaction and recognition memory.

\section{Notes}

Supplemental material for this article is available at http://www.afasci. $\mathrm{com} /$ publications/afasci-publications. Automated two-enclosure homecage social test and spontaneous activity and locomotion monitoring using the SmartCage system. This material has not been peer reviewed.

\section{References}

Aguirre M, Broughton R, Stuss D (1985) Does memory impairment exist in narcolepsy-cataplexy? J Clin Exp Neuropsychol 7:14-24. CrossRef Medline

Akbari E, Naghdi N, Motamedi F (2007) The selective orexin 1 receptor antagonist SB-334867-A impairs acquisition and consolidation but not retrieval of spatial memory in Morris water maze. Peptides 28:650-656. CrossRef Medline

Blouin AM, Fried F, Wilson C, Staba RJ, Behnke EJ, Lam HA, Maidment NT, Karlsson KA, Lapierre JL, Siegel JM (2013) Human hypocretin and melanin concentrating hormone levels are linked to emotion and social interaction. Nat Communications (in press).

Borgland SL, Taha SA, Sarti F, Fields HL, Bonci A (2006) Orexin A in the VTA is critical for the induction of synaptic plasticity and behavioral sensitization to cocaine. Neuron 49:589-601. CrossRef Medline

Bourtchuladze R, Frenguelli B, Blendy J, Cioffi D, Schutz G, Silva AJ (1994) Deficient long-term memory in mice with a targeted mutation of the cAMP-responsive element-binding protein. Cell 79:59-68. CrossRef Medline

Brotman MA, Rich BA, Guyer AE, Lunsford JR, Horsey SE, Reising MM, Thomas LA, Fromm SJ, Towbin K, Pine DS, Leibenluft E (2010) Amygdala activation during emotion processing of neutral faces in children with severe mood dysregulation versus ADHD or bipolar disorder. Am J Psychiatry 167:61-69. CrossRef Medline

Carter ME, Adamantidis A, Ohtsu H, Deisseroth K, de Lecea L (2009) Sleep homeostasis modulates hypocretin-mediated sleep-to-wake transitions. J Neurosci 29:10939-10949. CrossRef Medline

Chou TC, Lee CE, Lu J, Elmquist JK, Hara J, Willie JT, Beuckmann CT, Chemelli RM, Sakurai T, Yanagisawa M, Saper CB, Scammell TE (2001) Orexin (hypocretin) neurons contain dynorphin. J Neurosci 21:RC168. Medline

Corkin S, Sullivan EV, Carr FA (1984) Prognostic factors for life expectancy after penetrating head injury. Arch Neurol 41:975-977. CrossRef Medline

Crawley JN (2004) Designing mouse behavioral tasks relevant to autisticlike behaviors. Ment Retard Dev Disabil Res Rev 10:248-258. CrossRef Medline

Deadwyler SA, Porrino L, Siegel JM, Hampson RE (2007) Systemic and nasal delivery of orexin-A (Hypocretin-1) reduces the effects of sleep deprivation on cognitive performance in nonhuman primates. J Neurosci 27: 14239-14247. CrossRef Medline

de Lecea L (2010) A decade of hypocretins: past, present and future of the neurobiology of arousal. Acta Physiol (Oxf) 198:203-208. CrossRef Medline

de Lecea L, Kilduff TS, Peyron C, Gao X, Foye PE, Danielson PE, Fukuhara C, Battenberg EL, Gautvik VT, Bartlett FS 2nd, Frankel WN, van den Pol AN, Bloom FE, Gautvik KM, Sutcliffe JG (1998) The hypocretins: hypothalamus-specific peptides with neuroexcitatory activity. Proc Natl Acad Sci U S A 95:322-327. CrossRef Medline

Deng BS, Nakamura A, Zhang W, Yanagisawa M, Fukuda Y, Kuwaki T (2007) Contribution of orexin in hypercapnic chemoreflex: evidence from genetic and pharmacological disruption and supplementation studies in mice. J Appl Physiol 103:1772-1779. CrossRef Medline

Eriksson KS, Sergeeva OA, Haas HL, Selbach O (2010) Orexins/hypocretins and aminergic systems. Acta Physiol (Oxf) 198:263-275. CrossRef Medline

Fadel J, Burk JA (2010) Orexin/hypocretin modulation of the basal fore- 
brain cholinergic system: Role in attention. Brain Res 1314:112-123. CrossRef Medline

Gerashchenko D, Horvath TL, Xie X (2011) Direct inhibition of hypocretin/ orexin neurons in the lateral hypothalamus by nociceptin/orphanin FQ blocks stress-induced analgesia in rats. Neuropharmacology 60:543-549. CrossRef Medline

Geyer MA, Dulawa SC (2003) Assessment of murine startle reactivity, prepulse inhibition, and habituation. Curr Protoc Neurosci Chapter 8:Unit 8.17. CrossRef Medline

Guo Y, Feng P (2012) OX2R activation induces PKC-mediated ERK and CREB phosphorylation. Exp Cell Res 318:2004-2013. CrossRef Medline

Hanson LR, Frey WH 2nd (2008) Intranasal delivery bypasses the bloodbrain barrier to target therapeutic agents to the central nervous system and treat neurodegenerative disease. BMC Neurosci 9 [Suppl 3]:S5. CrossRef

Hara J, Beuckmann CT, Nambu T, Willie JT, Chemelli RM, Sinton CM, Sugiyama F, Yagami K, Goto K, Yanagisawa M, Sakurai T (2001) Genetic ablation of orexin neurons in mice results in narcolepsy, hypophagia, and obesity. Neuron 30:345-354. CrossRef Medline

Harris GC, Wimmer M, Aston-Jones G (2005) A role for lateral hypothalamic orexin neurons in reward seeking. Nature 437:556-559. CrossRef Medline

Henry GK, Satz P, Heilbronner RL (1993) Evidence of a perceptualencoding deficit in narcolepsy? Sleep 16:123-127. Medline

Ibi D, Nagai T, Koike H, Kitahara Y, Mizoguchi H, Niwa M, Jaaro-Peled H, Nitta A, Yoneda Y, Nabeshima T, Sawa A, Yamada K (2010) Combined effect of neonatal immune activation and mutant DISC1 on phenotypic changes in adulthood. Behav Brain Res 206:32-37. CrossRef Medline

Jaeger LB, Farr SA, Banks WA, Morley JE (2002) Effects of orexin-A on memory processing. Peptides 23:1683-1688. CrossRef Medline

Johnson PL, Truitt W, Fitz SD, Minick PE, Dietrich A, Sanghani S, TräskmanBendz L, Goddard AW, Brundin L, Shekhar A (2010) A key role for orexin in panic anxiety. Nat Med 16:111-115. CrossRef Medline

Kaidanovich-Beilin O, Lipina T, Vukobradovic I, Roder J, Woodgett JR (2011) Assessment of social interaction behaviors. J Vis Exp.

Khroyan TV, Zhang J, Yang L, Zou B, Xie J, Pascual C, Malik A, Xie J, Zaveri NT, Vazquez J, Polgar W, Toll L, Fang J, Xie X (2012) Rodent motor and neuropsychological behaviour measured in home cages using the integrated modular platform SmartCage ${ }^{\text {TM }}$. Clin Exp Pharmacol Physiol 39: 614-622. CrossRef Medline

Kilduff TS (2005) Hypocretin/orexin: maintenance of wakefulness and a multiplicity of other roles. Sleep Med Rev 9:227-230. CrossRef Medline

Kogan JH, Frankland PW, Silva AJ (2000) Long-term memory underlying hippocampus-dependent social recognition in mice. Hippocampus 10:47-56. CrossRef Medline

McClure EB, Pope K, Hoberman AJ, Pine DS, Leibenluft E (2003) Facial expression recognition in adolescents with mood and anxiety disorders. Am J Psychiatry 160:1172-1174. CrossRef Medline

McGregor R, Wu MF, Barber G, Ramanathan L, Siegel JM (2011) Highly specific role of hypocretin (orexin) neurons: differential activation as a function of diurnal phase, operant reinforcement versus operant avoidance and light level. J Neurosci 31:15455-15467. CrossRef Medline

Moy SS, Nadler JJ, Perez A, Barbaro RP, Johns JM, Magnuson TR, Piven J, Crawley JN (2004) Sociability and preference for social novelty in five inbred strains: an approach to assess autistic-like behavior in mice. Genes Brain Behav 3:287-302. CrossRef Medline

Nadler JJ, Moy SS, Dold G, Trang D, Simmons N, Perez A, Young NB, Barbaro RP, Piven J, Magnuson TR, Crawley JN (2004) Automated apparatus for quantitation of social approach behaviors in mice. Genes Brain Behav 3:303-314. CrossRef Medline

Naumann A, Bellebaum C, Daum I (2006) Cognitive deficits in narcolepsy. J Sleep Res 15:329-338. CrossRef Medline

Nomoto M, Takeda Y, Uchida S, Mitsuda K, Enomoto H, Saito K, Choi T, Watabe AM, Kobayashi S, Masushige S, Manabe T, Kida S (2012) Dysfunction of the RAR/RXR signaling pathway in the forebrain impairs hippocampal memory and synaptic plasticity. Mol Brain 5:8. CrossRef Medline

O’Kane G, Kensinger EA, Corkin S (2004) Evidence for semantic learning in profound amnesia: an investigation with patient H.M. Hippocampus 14: 417-425. CrossRef Medline

Perello M, Sakata I, Birnbaum S, Chuang JC, Osborne-Lawrence S, Rovinsky SA, Woloszyn J, Yanagisawa M, Lutter M, Zigman JM (2010) Ghrelin increases the rewarding value of high-fat diet in an orexin-dependent manner. Biol Psychiatry 67:880-886. CrossRef Medline

Peyron C, Tighe DK, van den Pol AN, de Lecea L, Heller HC, Sutcliffe JG, Kilduff TS (1998) Neurons containing hypocretin (orexin) project to multiple neuronal systems. J Neurosci 18:9996-10015. Medline

Reti IM, Reddy R, Worley PF, Baraban JM (2002) Selective expression of Narp, a secreted neuronal pentraxin, in orexin neurons. J Neurochem 82:1561-1565. CrossRef Medline

Riedel G, Kang SH, Choi DY, Platt B (2009) Scopolamine-induced deficits in social memory in mice: reversal by donepezil. Behav Brain Res 204: 217-225. CrossRef Medline

Rogers AE, Rosenberg RS (1990) Tests of memory in narcoleptics. Sleep 13:42-52. Medline

Rosin DL, Weston MC, Sevigny CP, Stornetta RL, Guyenet PG (2003) Hypothalamic orexin (hypocretin) neurons express vesicular glutamate transporters VGLUT1 or VGLUT2. J Comp Neurol 465:593-603. CrossRef Medline

Ryan BC, Young NB, Moy SS, Crawley JN (2008) Olfactory cues are sufficient to elicit social approach behaviors but not social transmission of food preference in C57BL/6J mice. Behav Brain Res 193:235-242. CrossRef Medline

Sakurai T, Amemiya A, Ishii M, Matsuzaki I, Chemelli RM, Tanaka H, Williams SC, Richardson JA, Kozlowski GP, Wilson S, Arch JR, Buckingham RE, Haynes AC, Carr SA, Annan RS, McNulty DE, Liu WS, Terrett JA, Elshourbagy NA, Bergsma DJ, et al. (1998) Orexins and orexin receptors: a family of hypothalamic neuropeptides and $\mathrm{G}$ protein-coupled receptors that regulate feeding behavior. Cell 92:573-585. CrossRef Medline

Sakurai T, Mieda M (2011) Connectomics of orexin-producing neurons: interface of systems of emotion, energy homeostasis and arousal. Trends Pharmacol Sci 32:451-462. CrossRef Medline

Scammell TE, Nishino S, Mignot E, Saper CB (2001) Narcolepsy and low CSF orexin (hypocretin) concentration after a diencephalic stroke. Neurology 56:1751-1753. CrossRef Medline

Selbach O, Bohla C, Barbara A, Doreulee N, Eriksson KS, Sergeeva OA, Haas HL (2010) Orexins/hypocretins control bistability of hippocampal long-term synaptic plasticity through co-activation of multiple kinases. Acta Physiol (Oxf) 198:277-285. CrossRef Medline

Sharf R, Guarnieri DJ, Taylor JR, DiLeone RJ (2010) Orexin mediates morphine place preference, but not morphine-induced hyperactivity or sensitization. Brain Res 1317:24-32. CrossRef Medline

Shirayama Y, Chaki S (2006) Neurochemistry of the nucleus accumbens and its relevance to depression and antidepressant action in rodents. Curr Neuropharmacol 4:277-291. CrossRef Medline

Siegel JM, Moore R, Thannickal T, Nienhuis R (2001) A brief history of hypocretin/orexin and narcolepsy. Neuropsychopharmacology 25:S14-S20. CrossRef Medline

Silva AJ, Kogan JH, Frankland PW, Kida S (1998) CREB and memory. Annu Rev Neurosci 21:127-148. CrossRef Medline

Stanley EM, Fadel J (2012) Aging-related deficits in orexin/hypocretin modulation of the septohippocampal cholinergic system. Synapse 66:445-452. CrossRef Medline

Tardito D, Musazzi L, Tiraboschi E, Mallei A, Racagni G, Popoli M (2009) Early induction of CREB activation and CREB-regulating signalling by antidepressants. Int J Neuropsychopharmacol 12:1367-1381. CrossRef Medline

Thonberg H, Fredriksson JM, Nedergaard J, Cannon B (2002) A novel pathway for adrenergic stimulation of cAMP-response-element-binding protein (CREB) phosphorylation: mediation via alphal-adrenoceptors and protein kinase C activation. Biochem J 364:73-79. Medline

Thor DH, Holloway WR Jr (1986) Caffeine and copulatory experience: interactive effects on social investigatory behavior. Physiol Behav 36: 707-711. CrossRef Medline

van Wimersma Greidanus TB, Maigret C (1996) The role of limbic vasopressin and oxytocin in social recognition. Brain Res 713:153-159. CrossRef Medline

Winsky-Sommerer R, Yamanaka A, Diano S, Borok E, Roberts AJ, Sakurai T, Kilduff TS, Horvath TL, de Lecea L (2004) Interaction between the corticotropin-releasing factor system and hypocretins (orexins): a novel circuit mediating stress response. J Neurosci 24:11439-11448. CrossRef Medline

Xie X, Smart TG (1994) Modulation of long-term potentiation in rat hip- 
pocampal pyramidal neurons by zinc. Pflugers Arch 427:481-486. CrossRef Medline

Xie X, Wisor JP, Hara J, Crowder TL, LeWinter R, Khroyan TV, Yamanaka A, Diano S, Horvath TL, Sakurai T, Toll L, Kilduff TS (2008) Hypocretin/ orexin and nociceptin/orphanin FQ coordinately regulate analgesia in a mouse model of stress-induced analgesia. J Clin Invest 118:2471-2481. CrossRef Medline
Xiong X, White RE, Xu L, Yang L, Sun X, Zou B, Pascual C, Sakurai T, Giffard RG, Xie X (2013) Mitigation of murine focal cerebral ischemia by the hypocretin/orexin system is associated with reduced inflammation. Stroke 44:764-770. CrossRef Medline

Yang M, Crawley JN (2009) Simple behavioral assessment of mouse olfaction. Curr Protoc Neurosci Chapter 8:Unit 8.24. CrossRef Medline 